\title{
To Determine The Knowledge And Attitudes On Modern Contraceptive Use Amongst Antenatal Attendees At The Niger Delta University Teaching Hospital, Okolobiri, South-South, Nigeria.
}

\author{
A.O Addah ${ }^{1}$, I.J Abasi ${ }^{2}$, E. H. Ikobho ${ }^{3}$, I. A. Ibrahim. ${ }^{4}$ \\ 1. Department of Obstetrics and Gynaecology, College of Health sciences/Niger Delta University \\ Amassoma,Bayesa State, Nigeria. \\ 2. Department of Obstetrics and Gynaecology, College of Health sciences/Niger Delta University Amassoma, \\ Bayelsa state Nigeria.
}

\begin{abstract}
Objective: To determine the knowledge, attitude on modern contraceptive use amongst antenatal attendees at the Niger Delta University Teaching Hospital, Okolobiri, Bayelsa state, Nigeria.

Materials and methods

This was a descriptive cross sectional study conducted at the Niger Delta University Teaching Hospital, Okolobiri, Bayelsa state, South-South Nigeria, between January and March, 2013. It consisted of a set of structured, pretested questionnaires that were administered to consecutive antenatal attendees.

Results:

A total number of 111 pregnant women were enrolled for the study. The mean age of respondents was 28.46 years \pm 4.88 with a range of 18-45 years. Eighty-two percent (82\%) of respondents in the study were aware of modern contraceptives. Seventy-nine respondents (71.3\%): N= 107 of respondents were able to identify the definition of contraception as a means of preventing pregnancy amongst other wrong definitions. Sixty respondents (54.1\%) have used one form of contraception before.

Conclusion

While awareness and knowledge of contraception was high on the surface, respondents have a poorunderstanding of what modern contraceptives are and stand for.

Key words:Attitude, Contraception, In-dept Knowledge, Knowledge, Contraceptive usage.
\end{abstract}

\section{Introduction}

Contraceptive usage improves women's health. Unintended pregnancies account for $40 \%$ of the 210 million annual pregnancies worldwide [1].An estimated one in five pregnancies is unplanned in Nigeria [2].These unintended pregnancies could be prevented if women use contraception. An estimated annual 448 million treatable sexually transmitted diseases[3] and over $80 \%$ of HIV [4] infections worldwide could also be prevented if women choose to use contraception. Socioeconomic conditions of families are also improved as contraceptive usage means fewer mouths to feed, clothe and less spending on children's education.

Nigeria has one of the lowest contraceptive prevalence in the world. Only about $15 \%$ of women [5] in their child bearing years embrace family planning in Nigeria. Nigeria contributes $10 \%$ [5] of world annual 20 million [6] abortion cases. An estimated 760,000 abortions occur each year in Nigeria resulting from unintended pregnancies dueto lack of contraceptive patronage [2]. Young women in their child bearing years bear the brunt of this carnage resulting from unsafe abortion [2]. The need for women to embrace contraception therefore cannot be over emphasised.

One issue peculiar to Nigeria as in many less developed countries is lack of spousal communications in matters relating to reproductive health with the result that such decisions are taken by the men folk and their families [7] Contraceptive usage is one of such issues. Due to the fact that there was no negotiation between the couples, men who have desires for a larger family will override their wives on such critical decisions that pertain to contraception. A number of studies conducted in different parts of Nigeria have confirmed that spousal influence on a contraceptive choice is a major issue $[7,8,9,10]$.In this study, we looked at these issues among others as contributory factors to none use of contraception.

While it is universally acclaimed that access to contraception is the key to reproductive and sexual health, studies have also shown that there are other barriers to contraceptive patronage in sub-Saharan Africa $[11,12,13]$. These barriers include women's knowledge and perception of contraception and the negative influence of culture on contraceptive patronage [11, 12, and 13]. While awareness to contraception is high amongst women in studies conducted in sub-Saharan Africa [14, 15], the depth of knowledge remain shallow and the benefits of contraception not easily realisable. Coupled with this fact are the erroneous beliefs amongst 
women that contraceptives are toxic chemicals that are injurious to the body [14]. Most women who do not use contraception do so because of perceived side effects. The cultural belief that children are God given and a woman must exhaust all the 'eggs' in her also creates a negative impact towards contraceptive patronage [16]. Religion also plays a role in non-contraceptive use. Some religious sects would advice their members against contraceptive usage because they believe it goes contrary to God's laid down rules for procreation [16].

We believe, to improve contraceptive prevalence in Nigeria, apart from high awareness that already existed, women need to have an in-depth knowledge of contraption and the benefits accruable to the individual from such patronage. While there is willingness to contraceptive patronage, this has not been matched by usage as demonstrated in many studies $[11,17]$

This study looks at the knowledge and attitude towards the use of modern day contraceptives amongst antenatal attendees and their degree of future willingness to use and the actual usage of contraception. This study was carried out at The Niger Delta University Teaching Hospital Okolobiri, Bayelsa, State, South-South, Nigeria. Pregnant women form a cohort of subjects where the uptake of contraception can be easily assessed as the antenatal period offers an opportunity to care givers where they can meet a sizeable population of women in their reproductive age to discuss issues pertaining to contraception.

This subject even though studied in some parts of South-South Nigeria, has not been conducted in Bayelsa state where the institution is sited.

The aim of this research is to compare our results with those of other researchers in this region and also with National figures. The results so obtained would allow us to advice policy makers on areas where to lay emphasis especially resource allocation. To alert care givers, doctors and nurses on which aspects of contraceptive usage they need to lay emphasis to improve contraceptive patronage with regards to advocacy, counselling and teaching on this subject.

\section{Methods}

This was a descriptive cross sectional study conducted at the Niger Delta University Teaching Hospital, Okolobiri, BayelsaState, South-South Nigeria, between August and November, 2013. It consisted of a set of structured questionnaires that were administered to consecutive antenatal attendees. The questionnaires were pretested on 20 antenatal mothers and corrections were made before they were formally administered to the target population of pregnant women. The questionnaires were administered by three interns working in the hospital. Mother's consent was sought and obtained before the questionnaires were administered to them. The top of their maternity records were marked so that the questionnaires cannot be administered twice to the same patient. There were no exclusion criteria. The questionnaires were administered to a total of 111 respondents.

The information sought included the biodata of respondents, if they were aware of contraception and if they do their source of information. The knowledge they have on contraception were tested by asking them to choose from a set of simplified objective questions on the definition of contraception and also choosing correct contraceptives from a list of substances.

\section{Results}

A total number of 111 pregnant women were enrolled for the study. There wereno exclusion criteria. The mean age of respondents was $28.46 \pm 4.88$ witha range of $18-45$ years. The median age of the respondents was 28 yearsand the range was $18-45$ years. The mean of the number of children/woman in the study was 2.45 . Only 9 women $(8.1 \%)$ and $7(6.3 \%)$ of women had 4 and $\geq 5$ children respectively. Thedemographic characteristics of respondents are shown Table 1 below.

Ninety-one $(82 \%)$ of respondents in the study were aware of modern contraceptives. Seventy-nine $(72.5 \%)$ of respondents heard about contraception from care providers (Doctors and Nurses), 18 (16.5\%) from friends, 5 $(4.5 \%)$ from the media.Table 2 shows source of information on contraception.

Fifty-two $(46.8 \%)$ have lectures and $43(38.7 \%)$ have been counselled on family planning in the course of this pregnancy.

The knowledge of respondents on modern contraceptives was tested by a series of objective structured questions. Forty respondents (36.4\%) erroneously identified the anti-malaria drug 'Quinine' as a contraceptive agent while another Forty-eight $(41.7 \%)$ of respondents said the alcoholic social drink popularly known as 'stout' is a means of emergency contraception. Thirty-two (29.6\%) respondents could not identify the daily pill. Seventy-nine respondents $(71.3 \%)-\mathrm{N}=107$ of respondents were able to identify the definition of contraception as a means of preventing pregnancy amongst other wrong definitions. Ninety-nine respondents $(89.2 \%)$ were able to identify the male condom as a means of contraception.

Table 3shows respondents knowledge on contraception.

Attitude of respondents to modern contraceptives: Ninety seven (84.3) respondents intend to limit the size of their families while $59(55.1 \%)$ said they will opt for a contraceptive method at the end of the pregnancy. Seventy one $(66.4 \%)$ of respondents discuss contraception with spouses and partners. Sixteen $(21.1 \%)$ has 
husband's refusal as a means of not using a modern contraceptive method. Only 11 (9.9\%) of respondents have ever visited a health facility to ask for contraception.

See Table 4 for respondents attitude towards contraceptive use.

Sixty respondents $(54.1 \%)$ have used one form of contraception before. A total of 57 (51.4\%) respondents were able to give the type of contraception used previously while $53(46.1 \%)$ did not give any response $-\mathrm{N} 110$.

The most popularly used modern contraceptive method was the male condom- a total of 33 respondents $(57.9 \%)$, used this contraceptive method. $\mathrm{N}=57$.

See Table 5 below for pattern of contraception used by respondents.

Table 6shows a cross tabulation of educational status versus contraceptive usage before the current pregnancy.. This was not statistically significant: $\mathrm{X}^{2}=0.188(\mathrm{P}<0.05)$.

The reasons for not embracing contraception are shown in table 7 below.

\section{Tables}

Table 1: Demographic Characteristics of Respondents

\begin{tabular}{|c|c|c|c|}
\hline Educational status & Frequency & Valid Percent & Cumulative Percent \\
\hline No formal education & 3 & 2.7 & 2.7 \\
\hline primary education & 12 & 10.8 & 13.5 \\
\hline secondary education & 51 & 45.9 & 59.5 \\
\hline tertiary education & 45 & 40.5 & 100.0 \\
\hline Total & 111 & 100.0 & \\
\hline \multicolumn{4}{|l|}{ Religion } \\
\hline Catholic & 21 & 18.3 & 22.6 \\
\hline Pentecostal & 78 & 67.8 & 90.4 \\
\hline Protestant & 4 & 3.5 & 93.9 \\
\hline Islam & 2 & 1.7 & 95.7 \\
\hline Jehovah witness & 5 & 4.3 & 100.0 \\
\hline Total & 115 & 100.0 & \\
\hline \multicolumn{4}{|l|}{ Parity } \\
\hline Primigavida & 37 & 33.6 & 33.6 \\
\hline araone & 28 & 25.5 & 59.1 \\
\hline Para two & 15 & 13.6 & 72.7 \\
\hline ara three & 14 & 12.7 & 85.5 \\
\hline ara four & 9 & 8.2 & 93.6 \\
\hline ara five and above & 7 & 6.4 & 100.0 \\
\hline Total & 110 & 100.0 & \\
\hline \multicolumn{4}{|l|}{ Marital status } \\
\hline Single & 13 & 11.7 & 11.7 \\
\hline Married & 95 & 85.6 & 97.3 \\
\hline Divorced/separated & 2 & 1.8 & 99.1 \\
\hline Widow & 1 & .9 & 100.0 \\
\hline Total & 111 & 100.0 & \\
\hline
\end{tabular}

Table 2: Source of information on contraceptive awareness

\begin{tabular}{llll} 
Doctors & 33 & 30.3 & 30.3 \\
Nurses & 46 & 42.2 & 72.5 \\
Parents & 2 & 1.8 & 74.3 \\
Friends & 18 & 16.5 & 90.8 \\
News papers & 2 & 1.8 & 92.7 \\
Radio/TV & 3 & 2.8 & 95.4 \\
Others & 5 & 4.6 & 100.0 \\
Total & 109 & 100.0 & \\
\hline
\end{tabular}

Table 3:Knowledge of contraceptives among respondents.

Yes

No

Total

Yes

No

3.00

Total

Contraception is a means of terminating a pregnancy

$\begin{array}{lll}15 & 14.2 & 14.2 \\ 91 & 85.8 & 100.0 \\ 106 & 100.0 & \end{array}$

Is a means of making a woman more fertile

$\begin{array}{lll}12 & 11.2 & 11.2 \\ 94 & 87.9 & 99.1 \\ 1 & .9 & 100.0 \\ 107 & 100.0 & \end{array}$




$\begin{array}{lccc} & \text { Is a means of preventing a woman from being pregnant } \\ \text { Yes } & 79 & 73.8 & 73.8 \\ \text { No } & 27 & 25.2 & 99.1 \\ 21.00 & 1 & .9 & 100.0 \\ \text { Total } & 107 & 100.0 & \end{array}$

Dilatation and Curettage or abortion is a means of family planning

$\begin{array}{llll}\text { Yes } & 14 & 13.1 & 13.1 \\ \text { No } & 93 & 86.9 & 100.0\end{array}$

Total

100.0

100.0

\begin{tabular}{llcl} 
& \multicolumn{3}{c}{ is a means of safe delivery } \\
Yes & 22 & 20.8 & 20.8 \\
No & 84 & 79.2 & 100.0 \\
Total & 106 & 100.0 &
\end{tabular}

Quinine is a contraceptive agent?

$\begin{array}{llll}\text { Yes } & 40 & 36.4 & 36.4 \\ \text { No } & 70 & 63.6 & 100.0 \\ \text { Total } & 110 & 100.0 & \end{array}$

Condom is a contraceptive agent?

$\begin{array}{llll}\text { Yes } & 99 & 90.0 & 90.0\end{array}$

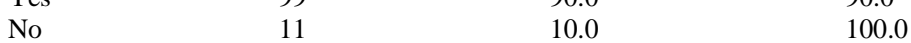

$\begin{array}{lll}\text { Total } & 110 & 100.0\end{array}$

Stout drink after sex is a means of preventing pregnancy?

$\begin{array}{llll}\text { Yes } & 48 & 43.6 & 43.6 \\ \text { No } & 62 & 56.4 & 100\end{array}$

$\begin{array}{lll}\text { Total } & 110 & 100.0\end{array}$

Daily pill is a contraceptive agent?

\begin{tabular}{llll} 
Yes & 76 & 70.4 & 70.4 \\
No & 32 & 29.6 & 100.0 \\
Total & 108 & 100.0 & \\
\hline
\end{tabular}

Table 4.Respondents attitude towards contraceptive usage Have you visited a health facility to ask for family planning before?

$\begin{array}{llll}\text { Yes } & 11 & 9.9 & 9.9 \\ \text { No } & 100 & 90.1 & 100.0 \\ \text { Total } & 111 & 100.0 & \\ \begin{array}{l}\text { Do you intend to limit the size of your family? } \\ \text { Yes }\end{array} & & \\ \text { No } & 97 & 87.4 & 87.4 \\ \text { Total } & 14 & 12.6 & 100.0 \\ & 111 & 100.0 & \end{array}$

Do you discuss contraception/ family planning with your partner/husband?

$\begin{array}{llll}\text { Yes } & 71 & 66.4 & 66.4 \\ \text { No } & 36 & 33.6 & 100.0 \\ & & & \\ \text { Total } & 107 & 100.0 & \end{array}$

Why did you stop contraception, was it side effect?

$\begin{array}{llll}\text { Yes } & 13 & 16.5 & 16.5 \\ \text { No } & 66 & 83.5 & 100.0 \\ \text { Total } & 79 & 100.0 & \end{array}$

At the end of the pregnancy will you opt for a contraceptive method

\begin{tabular}{llll} 
Yes & 59 & 55.1 & 55.1 \\
No & 42 & 39.3 & 94.4 \\
Not known & 6 & 5.6 & 100.0 \\
Total & 107 & 100.0 & \\
\hline
\end{tabular}


To Determine the Knowledge and Attitudes on Modern Contraceptive Use Amongst Antenatal...

Table 5: Pattern of contraceptive usage by respondents before the current pregnancy

\begin{tabular}{llll}
\hline Male Condom & 33 & 57.9 & 57.9 \\
Daily pill & 8 & 14.0 & 71.9 \\
Injection & 10 & 17.5 & 89.5 \\
Postinor & 6 & 10.5 & 100.0 \\
Total & 57 & 100.0 & \\
\hline
\end{tabular}

Table 6: Education status versus contraceptive usage before pregnancy

\begin{tabular}{|c|c|c|c|c|}
\hline & & \multicolumn{2}{|c|}{ Contraceptive usage? } & \multirow[t]{2}{*}{ Total } \\
\hline & & Yes & No & \\
\hline \multirow{4}{*}{ education status } & No formal education & 1 & 2 & 3 \\
\hline & primary education & 6 & 6 & 12 \\
\hline & secondary education & 23 & 27 & 50 \\
\hline & tertiary education & 30 & 15 & 45 \\
\hline Total & & 60 & 50 & 110 \\
\hline
\end{tabular}

$$
\mathrm{X}^{2}=0.188(\mathrm{P}<0.05)
$$

Table 7: Reasons for not using contraception

To resume child bearing?

\begin{tabular}{|c|c|c|c|}
\hline & Frequency & Percent & Cumulative Frequency \\
\hline Yes & 39 & 52.7 & 52.7 \\
\hline No & 34 & 45.9 & 98.6 \\
\hline 22 & 1 & 1.4 & 100.0 \\
\hline Total & 74 & 100.0 & \\
\hline No response & 37 & & \\
\hline \multicolumn{4}{|l|}{ Side effect? } \\
\hline Yes & 13 & 16.5 & 16.5 \\
\hline No & 66 & 83.5 & 100.0 \\
\hline Total & 79 & 100.0 & \\
\hline No response & 32 & & \\
\hline \multicolumn{4}{|l|}{ The Cost? } \\
\hline Yes & 5 & 6.6 & 6.6 \\
\hline No & 71 & 93.4 & 100.0 \\
\hline Total & 76 & 100.0 & \\
\hline No response & 35 & & \\
\hline \multicolumn{4}{|c|}{ Unavailability? } \\
\hline Yes & 38 & 33.5 & 33.5 \\
\hline No & 73 & 63.5 & 100.0 \\
\hline Total & 115 & 100.0 & \\
\hline \multicolumn{4}{|c|}{ Background medical illness? } \\
\hline Yes & 7 & 9.7 & 9.7 \\
\hline No & 65 & 90.3 & 100.0 \\
\hline Total & 72 & 100.0 & \\
\hline \multicolumn{4}{|c|}{ Husband / partner refusal? } \\
\hline Yes & 16 & 21.1 & 21.1 \\
\hline No & 60 & 78.9 & 100.0 \\
\hline Total & 76 & 100.0 & \\
\hline No response & 35 & & \\
\hline
\end{tabular}

\section{Discussion}

Studies from developing countries have shown that socio-demographic characteristics are some of the predictors of an individual's contraceptive choice [18]. The mean age for the study population was $28-3 \pm 4.97$ and a median of 28 years. This means that half (50\%) of the study population will in the next 21 years still be in the reproductive age group (15-49 years), and would require one form of contraception or the other to control their fertility. The mean parity of the $64 \%$ respondents who have delivered previously was 2.5 . This means that on the average, these respondents have 2-3 children per individual and therefore will require a contraceptive method to delay, postpone or terminate child bearing. It is therefore necessary to ascertain the knowledge and the attitude of this study population towards contraceptive uptake. 
The study population had good literacy level as $45.9 \%$ and $40 \%$ of respondents have secondary and tertiary education respectively. The benefit of this is that they are more likely to posses the ability to understand health promotions in general and on contraception at the antenatal clinics, media, contraceptive awareness programmes, from posters and brochures. The predominantly Christian dominated South-South geopolitical zone in Nigeria reflectedin the study group as $98.2 \%$ were Christians. Seventy- eight $70.3 \%$ ) and $18.9 \%$ respondents were of the Pentecostal and Catholic faiths respectively. These variations in religious affiliations and ideology in the study population could also shape their beliefs, attitude and practice of contraceptive usage ${ }^{16 .}$

The awareness in the study group was very high, as $82 \%$ of respondents have heard about contraceptives. The awareness on modern contraceptive methods in Nigeria has grown over time. This is because this result is in contrastto the Nigerian Demographic and Health Survey (2003) where more than half $(56 \%)$ of Nigerian women aged between 15-49 years had never heard a message on family planning methods [19]. The source of information for respondents was mostly hospital based-71\% respondents heard of family planning from doctors and nurses. This high awareness is due to the high literacy rate among the study group and the health education and counselling from doctors and nurses during antenatal visits. Knowledge regarding the concept of family planning reflects the effectiveness of the educational sessions offered by health care providers in the area in general and in the study group in particular.[20].

One of the greatest obstacles to family planning in developing countries is knowledge. An individual can only accept to take contraceptives if she has an in-depth knowledge of what contraception are the side effects and above all the benefits accruing to the individual for using it. Health risks associated with contraception are low compared with risks associated with unintended and pregnancy complications in general, unsafe abortion in particular. On the surface of it, the study population of antenatal patients have good knowledge about contraception as $71 \%$ were able to identify correctly the definition of contraception among other structured objective questions. They were able to identify at least one or two contraceptive methods (Condom $89.2 \%$ and daily pill $68.9 \%$ ). These results were similar to works done in Tanzania where $80 \%$ of respondents knew at least three modern contraceptive methods [21]. However, the in-depth knowledge ofmodern contraceptive methods among respondents in thestudy remain shallow because when challenged further on this subject, 36.9\% said the anti, - malaria drug, Quinine can be used for contraception. A further $43.3 \%$ said the social alcoholic beverage 'stout drink' can be used as an emergency contraceptive agent. Advocacy by care providers, Social workers, Non-Governmental Organisations (NGOs), various Governments in Nigeria need to be intensified to improve the knowledge and acceptance of modern contraceptive methods.Only $46.8 \%$ of the antenatal mothers in this study population had health education talks from care providers on family planning in the course of the pregnancy. Only $37.7 \%$ have been counselled on various contraceptive methods in the course of the pregnancy. Even though this study is not enough to generalize, care providers in Nigeria need to do more to improve the uptake of contraception in the country.

The attitude of the study group was favourably disposed to contraceptive patronage. This is because $84.3 \%$ of respondents intend to limit their family size; another $55.1 \%$ said they will opt for a contraceptive method at the end of the current pregnancy. Spousal communications in matters related to contraceptive choice which has featured prominently in studies in Nigeria did not feature in this study group as $64.4 \%$ of respondents discuss contraception with spouses and partners. However, this high degree of enthusiasmtowards contraceptive patronage did not transform to usage as only $9.9 \%$ of respondents have voluntarily walked up to a health facility to ask for contraception.

The contraceptive usage by the study population before the advent of the current pregnancy was 54 $\%$.These results are well above the current National average where only $15 \%$ of married women are using modern contraceptive methods [5]. This disparity may be due to the fact that the antenatal clinics are pools of pregnant women who are consistently receiving heath education talks on various subjects, family planning inclusive from care providers. The most widely used family planning method was the male condom (33\%), followed by the injectables $(95 \%)$.

\section{Conclusion}

The current prevalence of modern contraceptive use in Nigeria is low because while the awareness and knowledge are high, the in-depth knowledge of contraception is very shallow as shown in this study. Would be acceptors can only be convinced to use modern contraceptive methods if they have adequate knowledge and the benefits of using these substances. They must be clear in their minds that the side effects of modern day contraceptives are low compared to the risks associated with carrying an unintended pregnancy and unsafe abortion with all its complications As it stands today in Nigeria, there is an unmet needs of contraceptive use amongmarried women between the ages of 15-49 years who want to use contraception, but the will to do is not there.

\section{References}


[1]. SSingh, G. Sedgh G, R. Hussain, Unintended pregnancy: worldwide levels, trends, andoutcomes, Stud FamPlann, 41, 2010, 241-250.

[2]. A Bankole A, et al, Unwanted Pregnancy and Induced abortion in Nigeria: Causes and consequences, New York, Guttmacher Institute, 2006.

[3]. Prevalence and incidence of selected sexually transmitted infections. Chlamydia, Neisseria gonorrhoea, Syphilis and Trichomonasvaginalis. Geneva, World Health Organization, 2011.

[4]. Sexual and reproductive health and HIV/AIDS linkages: a framework for priority linkages. Geneva: World Health Organization, United Nations Population Fund, International Planned Parenthood Federation, Joint United Nations Programme on HIV/AIDS, 2005

[5]. Nigerian Demographic and Health Survey (NDHS) - Interim Report, 2013.

[6]. S.K. Henshaw, S. Singh, H. Taylor, The incidence of Abortion Worldwide, Family Planning Perspectives, Volume 25, Supplement, January, 1999.

[7]. P.O Ogunjuyigbe, E.O. Ojofeitimi, A. Liasu, Spousal communications, changes in partner attitude and contraceptive use among the Yorubas of Southwest Nigeria. J. Soc. Sci., 6(1), 2000, 59-64.

[8]. C.U Iklaki, J.E Ekabua, A. Abasiattai A, et al, Spousal communication in contraceptive decisions among antenatal patients in Calabar, South Eastern, Nigeria, Niger J. Med.,14(4), 2005, 405-407.

[9]. M.Y. Ijadunola, T.C. Abiona, K.T. Ijadunola, O.T Afolabi, O.A Esimai et al, Male involvement in family planning decision making in Ile- Ife, Osun State, Nigeria,AfrReprod Health, 14(4), 2020, 405-7.

[10]. C Izugbara,L. Ibisomi, A.C. Ezeh, M. Mandara, Gendered interests and poor contraceptive communication in Islamic Northern Nigeria, J FamPlannReprod Health care, 36(4), 2010, 19-24

[11]. E Asekun-Olarinmoye, W. Adebimpe, J. Bamidele, O. E.T Odu, et al, Barriers to use of modern day contraception among women in an inner city area of Osogbo metropolis, Osun State Nigeria.Int J Women's Health, 11(5), 2012, 647-55.

[12]. A.M. Sunmola, Evaluating the sexual behaviour, barriers to condom useand its actual use by university studentsin Nigeria, AIDS Care, 17(4), 2005, 437-65.

[13]. C Ujulu, J. Anyanti, S.B Adebayo, F. Muhammad, O. Oluigbo, A. Gofwan,Religion, Culture and male involvement in the use of standard days method: evidence from Enugu and Kastina Statesof Nigeria. IntNurs., Rev.,58 (4), 2011, 484-90.

[14]. A .C Ikeme, H.U. Ezegwui HU, Uzodimma AO. Knowledge,attitude and use of emergency contraception among female undergraduates in Eastern Nigeria. J ObstetGynaecol. 2005; 25.(5): 491-3.

[15]. K Okanlawon, M. Reeves, O. P. Agbaje. Contraceptive use : Knowledge,Perception and attitude of Refugee Youths in Oru Refugee Camp, Nigeria. AfrReprod Health, 14 (4), 2010, 26.

[16]. U Igbudu U, S. O. Okoedion, E.B. Peremene, K. A. Eghafona, Religious beliefs and Family Planning Practices of married women in Zone 5, Police Barracks in Nigeria,Ozean Journal of Social Sciences, 4(2), 2011, 56.

[17]. A. A. Aliyu, A. U. Shehu, M.N. Sambo, K.Sabitu, Contraceptive knowledge, Attitude and Practice among married women in Samaru Community, Zaria, Nigeria, 7 (4),2010, 342-4.

[18]. C.A. Okezie, A.O. Ogbe,C.R.Okezie. Socio - demographic determinants of contraceptive use among rural women inIkwuano Local Government Area of Abia State, Nigeria. Int'1 NGO Journal, 5(4),2010. 74-77.

[19]. Nigeria Demographic and Health Survey 2003.KanarNael Amin ALqadi. Knowledge, Attitude and Practice of Palestenian Women Refugee Camps of Nablus Area Towards Family Planning.2004. Al Najah National University. Unpublished work.JLwelamira, G. Muyamagola, M.M. Msaki, Knowledge, Attitude and Practice (KAP) Towards

[20]. ModernContraception Among married women of Reproductive age in Mpwapwa District, Central Tanzania, Current Research Journal of Social Sciences, 4 (3), 2012, 235-245.KanarNael Amin ALqadi. Knowledge,Attitude and Practice of Palestenian Women Refugee Camps of Nablus Area Towards Family Planning.204. Al Najah National University. Unpublished work. 